Preference is given to letters commenting on contributions published recently in the JRSM. They should not exceed 300 words and should be typed double spaced

\section{The pain of venous cannulation}

I was so glad to read Dr Yentis's editorial (April 2005 $J R S M^{1}$ ), with its message that the pain of venous cannulation is far from trivial. Last year I underwent six cycles of chemotherapy for breast cancer, and thus required six cannulation procedures. Like most patients I feared themwould I get the nurse/doctor who was good at them or would I get the one who jagged a nerve on the first occasion and left me with pins and needles in my hand for six months? - but I endured them with a grimace and a sigh of relief once the things were in. I also knew that PICC and Hickman lines would only be offered as a last resort, even though one of the drugs, epirubicin, is caustic to veins and notorious for making subsequent cannulations more difficult.

True to form, epirubicin seemed to turn my veins to leather or wood; and, because I had had lymph nodes removed, only one arm was suitable for cannulation. The lack of access sites might not have been so serious had I not subsequently developed a brain tumour. This meant a total of five CT, MRI and bone scans within one week, all of which required a cannula. Although the veins were visible, at best several very painful attempts at cannulation were needed and usually I ended up having a paediatric cannula inserted (and I'm no screamer). I asked repeatedly for anaesthetic cream to be applied-Dr Yentis' injection method would, of course, be much quicker - but each time I was studiously ignored. It seemed that the nurses and doctors had decided I was being a wimp and they were going to get the thing into me, come what might.

The only person who actually heard what I said was the sister on the ward where I stayed when I had my brain tumour removed. She applied a local anaesthetic cream and the final CT went like a dream; and the cannula was left in place for the anaesthetist to use the next day.

\section{Sharon Dorrell}

Top Floor, 32 Umfreville Road,

Haringey, London N4 1SB, UK

E-mail: Sharon@shazdor.co.uk

\section{REFERENCE}

1 Yentis S. Taking the sting out of needles. J R Soc Med 2005;98:139-40

Dr Sado and Dr Deakin (April 2005 JRSM $^{1}$ ) refer to some of the practical reasons why ward doctors are less likely than anaesthetists to use local anaesthesia for vein cannulation. ward doctor might have to insert up to twenty cannulas; and, if on each occasion the lidocaine has to be produced from a locked cupboard by a nurse, time does not permit. However, time is not the issue here. I do not accept Sado and Deakin's conclusion that patients are suffering 'more pain than necessary'. Assessing the effect of local anaesthesia for vein cannulation, Rohm et al. ${ }^{2}$ in a recent study, found clear benefits for cannulae of $16 \mathrm{G}$ or greater but no advantages for $18 \mathrm{G}$ (green) and $20 \mathrm{G}$ (pink). These smaller cannulae are the ones used most often on the ward. If a $14 \mathrm{G}$ cannula is needed, this will probably be an emergency where local anaesthesia would unduly delay treatment. The arguments of Sado and Deakin are hazardous because they could be used unfairly in medicolegal cases. I see no argument for use of local anaesthesia in routine ward cannulation.

\section{Michelle Petrou}

2 Langside Crescent,

London N14 7DR, UK

E-mail: michellepetrou@doctors.org.uk

\section{REFERENCES}

1 Sado DM, Deakin CD. Local anaesthesia for venous cannulation and arterial blood gas sampling: are doctors using it? J R Soc Med 2005; 98: $158-60$

2 Rohm KD, Schollhorn TA, Gwosdek MJ, Piper SN, Maleck WH, Boldt J. Do we necessarily need local anaesthetics for venous cannulation? A comparison of different cannula sizes. Eur J Anaesthesiol 2004;21:214-16

\section{Cardiac revascularization}

Lindsay John needs to be congratulated for his rational, balanced review of revascularization techniques (January $2005 J R S M^{1}$ ). Twenty years ago all coronary patients were referred to the surgeons. Today most undergo angioplasty and stenting, despite recognition that surgical results are generally superior and probably not now much more costly. Furthermore, the surgical approach is more comprehensive, requires less reinvestigation and is more globally acceptable. In opposition, interventional cardiologists have accepted a constant restenosis rate, an occasional irretrievable balloon and more recently stent thrombosis reports. ${ }^{2}$ Ongoing haemorrhagic risks associated with antiplatelet agents cannot be ignored and repeated radiation exposure is hazardous to both patients and operators.

There are other considerations: what is the long term effect of metallic intrusions inside arteries? What happens when the eluting substances become depleted? As Lindsay John correctly remarks, when those stented patients eventually reach the surgeons, suitable sitings for bypass conduits can become problematic. 
David Taggart in a recent article favours surgery over percutaneous interventions for severe coronary artery disease. $^{3}$ I believe he is right. At best angioplasty is a time-buying operation with limited benefits. It might be more profitable for our patients if interventional cardiologists instead of becoming robotic technocrats returned to basic, unbiased clinical assessment and management and provided more supportive efforts in the aftercare of patients requiring coronary surgery. They need to candidly consider the benefits to the patients rather than apply their skills to achieve the often unachievable. The pendulum it seems has swung from one extreme to the other. It is high time to adopt a median standpoint.

\section{Romeo J Vecht}

118 Maida Vale, London W9 1PT, UK

E-mail: r.vecht@virgin.net

\section{REFERENCES}

1 John LCH. Cardiac revascularization - a need for independent decision makers. J R Soc Med 2005;98:1

2 McFadden EP, Stabile E, Regan E, et al. Late thrombosis in drug eluting coronary stents after discontinuation of anti-platelet therapy. Lancet 2004;364:1519-21

3 Taggart DP. Surgery is the best intervention for severe coronary artery disease. BMJ 2005;330:785-6

\section{Magnets}

Dr Rice and colleagues (March $2005 J R S M^{1}$ ) describe a case in which small disc magnets proved very difficult to remove from a child's penis. We have met with a similar case affecting the nasal septum. ${ }^{2}$

A man of 37 was part of the cast of a pantomime and was wearing costume earrings with magnetic clips, one in each nostril. During the performance he sustained a knock that broke the ornament from both clips simultaneously. The magnetic clips were then attracted to each other and lodged on either side of the septum, in exactly opposite positions. He attended ENT outpatients just over 24 hours later and, under the microsope, the magnetic discs were eased apart. Like Rice and co-workers we employed a shearing movement, using nasal dressing forceps to shift the two magnets perpendicular to the force of attraction. This was performed without much difficulty. The underlying nasal septal mucosa had been eroded on both sides of the septum and both magnets were lying directly on the septal cartilage. Despite local medical treatment, a small septal perforation developed. The patient was considered for a septal plug/grommet but, being symptom-free, he was not keen.

Ahmes L Pahor

ENT Department, City Hospital NHS Trust, Birmingham B18 7QH, UK

\section{REFERENCES}

1 Rice SA, Rajan P, Hansen R, Munro FD. Painful attraction: a magnetic penile injury. J R Soc Med 2005;98:122-3

2 Umaria N, Chavda SV, Pahor AL. An unusual cause of nasal septum perforation. J Laryngol Otol 1999;113:1020-1

Dr Rice and colleagues (March $2005 J R S M^{1}$ ) describe an incident in which two 'rare earth magnets' became attached to the penis of an unfortunate juvenile and proved very difficult to remove. These magnets are sold in Canada (Lee Valley) with not only a warning concerning their use and storage but also a clear description of how to separate two or more such magnets by, as the authors eventually discovered, the use of a shearing force. The package insert suggests a piece of wood with a hole a little larger than the magnet held under one magnet, while a shearing force with another piece of wood is used to push the uppermost magnet away. The insert warns that the magnets may, if applied to the skin, 'raise a blood blister if you don't control them well'. As far as I am aware, no Canadian Provincial Health Department is recommending the application of magnets to any part of the human frame for any reason!

\section{Andrew Watson}

PEI Department of Health, Montague, PEI, Canada COA 1RO

\section{REFERENCE}

1 Rice SA, Rajan P, Hansen R, Munro FD. Painful attraction: a magnetic penile injury. J R Soc Med 2005;98:122-3

\section{Emergency airway management in the UK}

Colin Graham, in his review article (March 2005 JRSM $^{1}$ ), revisits the suggestion that all airway interventions in UK emergency departments could be managed by emergency physicians. If training of emergency physicians is standardized to six months in anaesthesia and six months in critical care, they would acquire only rudimentary skills in basic airway management and the conduct of anaesthesia. There is widespread use of the laryngeal mask airway, considerable decrease in working hours, and the need to concurrently teach anaesthesia trainees, paramedics, etc. In only six months trainees would participate in approximately 350 cases, on average performing less than 2 endotracheal intubations per week. Few of these will be in emergency circumstances. ${ }^{2-4}$

If anaesthesia experience mainly continues in emergency departments where 2 trauma patients will require rapid sequence intubation per month ${ }^{5}$ trainees cannot maintain their skills. How indeed are their consultants to revalidate as trainers? They must be able to predict and act immediately whenever there is difficulty. How will they recognize the difficult airway and call an anaesthetist early 
when even the most thorough examination is only $71 \%$ sensitive? ${ }^{6}$

It is one thing to intubate a patient following cardiac arrest and another to anaesthetize and intubate a patient on the brink of an arrest. Currently there is an inappropriate degree of self-confidence amongst emergency department trainees, despite their experience in emergency anaesthesia. ${ }^{7}$ So how can we best develop and maintain their skills despite infrequent exposure?

I believe the answer is to regularly repeat anaesthesia training blocks, perhaps one training list per month. In addition, written, practical, and simulator testing for recertification ensures maintenance of skills. ${ }^{8,9}$ Anaesthesia emergencies are uncommon. Therefore knowledge or clinical experience, lacking in those not formally trained, could only become apparent in very large outcome studies. ${ }^{10,11}$

\section{Andrew C Steel}

Department of Anaesthesia, Royal Brompton Hospital, London, UK

\section{REFERENCES}

1 Graham CA. Emergency department airway management in the UK. $J$ R Soc Med 2005;98:107-10

2 Abdalla S, Thompson KD. Away with the LMA? Anaesthesia 1999;54: 1116-17

3 Sim DJ, Wrigley SR, Harris D. Effects of the European Working Time Directive on anaesthetic training in the United Kingdom. Anaesthesia 2004;59:781-4

4 Tomlinson A. Effects of the EWTD on anaesthetic training in the UK. Anaesthesia 2005;60:96-7

5 Butler JM, Lecky F, Townend WJ, Bouamra O, Woodford M. Intubations in trauma patients in UK emergency departments [Abstract]. Annual Scientific Meeting of the Faculty of Accident and Emergency Medicine, London, November 2001: A11

6 Wilson ME. Predicting difficult intubation. Br J Anaesth 1993;71: 333-4

7 Graham CA, Thakore SB, Mattick AP, Docherty E, Wares GM. Rapid sequence intubation: a survey of senior and middle grade staff in Scotland [Abstract]. J Accid Emerg Med 2000;17:71

8 Thalman JL, Rinaldo-Gallo S, MacIntyre NR. Analysis of an endotracheal intubation service provided by respiratory care practitioners. An experience of 10 years at Duke University Medical Center, SC. Respiratory Care 1993;38:469-73

9 Bishop MJ, Michalowski P, Hussey JD, Massey L, Lakshminarayan S. Recertification of respiratory therapists' intubation skills every year after initial training: analysis of skill retention and retraining. Respiratory Care 2001;46:234-7

10 Graham CA, Beard D, Oglesby A, et al. Rapid sequence intubation in Scottish urban emergency departments. Emerg Med J 2003;20:3-5

11 Schwartz DE, Matthay MA, Cohen NH. Death and other complications of emergency airway management in critically ill adults. A prospective investigation of 297 tracheal intubations. Anesthesiology 1995;82: $367-76$

\section{How to pass exams: evidence-based advice?}

The enjoyable article by Mr Cascarini and Dr Irani (April $2005 \mathrm{JRSM}^{1}$ ) outlines the authors' personal viewpoints on how to pass postgraduate clinical exams. This prompts me answer is maybe just a little. There is some evidence that getting organized early helps medical students to pass. ${ }^{2}$ Wright and Tanner found that students who were sufficiently organized to fulfil simple administration tasks during their course were more likely to pass. This research was subject to confounding factors and was done on medical students but the results might reasonably be extrapolated to postgraduate students. What about advice on how best to study? McManus et al. ${ }^{3}$ found that medical students' success in their final examination was related to a strategic or deep learning style in the final years. Students with such styles are best able to relate ideas to evidence and to integrate material across courses; they also are ambitious to achieve high grades. But worryingly, in this survey, success in the final examination was not related to a student's clinical experience, so the exam itself might not be valid. The fact that pass rates for Royal College exams are $44-79 \%$ for British graduates and 28-67\% for non-British graduates ${ }^{4}$ has prompted some to cry racism, but the likely reason for the difference is that British-educated doctors have better English and know the system.

Overall there are precious few hard facts and figures in this area. The high failure rates in postgraduate exams suggest an enormous need for research. ${ }^{4}$ If we knew the internal and external factors that influence success in exams we might begin to offer evidence-based advice.

\section{Kieran Walsh}

8 Elmhurst Villas, Cheltenham Road, London SE15 3AE, UK

E-mail: kmwalsh@bmjgroup.com

\section{REFERENCES}

1 Cascarini L, Irani M. Surviving a clinical exam: a guide for candidates. $J$ R Soc Med 2005;98:174-7

2 Wright N, Tanner MS. Medical students' compliance with simple administrative tasks and success in final examinations: retrospective cohort study. BMJ 2002;324:1554-5

3 McManus IC, Richards P, Winder BC, Sproston KA. Clinical experience, performance in final examinations, and learning style in medical students: prospective study. BMJ 1998;316:345-50

4 Donaldson L. Unfinished Business: Proposals for the Reform of the Senior House Officer Grade. London: Department of Health, 2002 [www.doh.gov.uk/shoconsult]

\section{Goodbye mercury}

Goodbye mercury? I should hope so, and not only for the reasons cited by Dr Varughese and Professor Lip in their editorial (March $2005 J R S M^{1}$ ). Pressure is defined scientifically as force per unit area. Expression of pressure in this way gives a much better perception of the force being exerted on arterial walls than does the height of a column of mercury.

Meteorologists now express atmospheric pressure in terms of the pascal, where the former millimetre of 
mercury becomes 1.33 hectopascal. Along with the mercury itself let us abandon the archaic millimetre of mercury and adopt the hectopascal.

\section{David Sowby}

39 Knocksinna Crescent, Dublin 18, Ireland

E-mail: dsowby@gofree.indigo.ie

\section{REFERENCE}

1 Varughese GI, Lip GYH. Goodbye to mercury? Blood pressure measurement and its future. J R Soc Med 2005;98:89-90

\section{Ganglioneuromas in the adult scrotum}

Reporting on a patient with paratesticular ganglioneuromas Mr Hanna and his colleagues (February $2005 J^{\prime R S M} M^{1}$ ) recommend imaging of the retroperitoneum in such cases because of the common embryological origin of scrotum and retroperitoneum. We disagree with their embryology. The scrotum develops as follows: between the sixth and eighth weeks of development, a pair of swellings (cloacal folds) appear on either side of the cloacal membrane. The folds meet anterior to this membrane to form the genital tubercle. ${ }^{2}$ The peritoneum divides the cloacal membrane into a urogenital membrane and an anal membrane. This also separates the cloacal fold into a urethral fold and an anal fold. Then, a pair of labia-scrotal swellings appear, which ultimately develop into a male scrotum. ${ }^{3}$ By contrast, the ganglionic crest will be constituted, in the mesoblast space, from the ectoblast, from each side of the neural tube on the whole length of the notochord, as metamerized bands to give the matrix of the sympathetic (from which paratesticular ganglioneuromas arise) and parasympathetic nervous system.

\section{Ali Thwalni \\ Ravi Kumar \\ Iqbal Shergill \\ St Bartholomew's Hospital, London, UK}

\section{REFERENCES}

1 Hanna SJ, Muneer A, Cohill SB, Miller MAW. Ganglioneuromas in the adult scrotum. J R Soc Med 2005;98:63

2 Larssen WJ. Essentials of Human Embryology. 2004:276

3 Dr Mark Hill. Development of the Kidneys and Reproductive System. UNSW Embryology, 2004 [embryology.med.unsw.edu.au]. Accessed 4 April 2005

\section{Emergency care for complainants of sexual assault}

Dr Wiese and his colleagues (February $2005 J R S M^{1}$ ) provide a reasonable overview of sexual assault examination practice in emergency departments. They are incorrect, however, in coupling Australia with the USA in the use of specially trained sexual assault nurse examiners. Sexual assault forensic services throughout Australia are almost exclusively provided by doctors, most of whom have training and experience in this field. At present there is no move to transfer such services to forensic nurse examiners, except in circumstances where there are significant difficulties in the availability of medical practitioners, as is found in rural and remote parts of Australia. The authors are most accurate when implying that sexual assault services (and indeed all forensic services) should be provided by practitioners with specialist qualifications or training. The implementation of forensic nurse examiners in rural and remote Australia will proceed only after specialist training in the appropriate fields.

\section{Angela Williams \\ Victorian Institute of Forensic Medicine, \\ 11 Moore St, Southbank VIC 3006, Australia \\ E-mail: angelac@vifm.org}

\section{REFERENCE}

1 Wiese M, Armitage C, Delaforce J, Welch J. Emergency care for complainants of sexual assault. J R Soc Med 2005;98:49-53

\section{Conjoined twins}

I was pleased to see the reference to the Blazek sisters in Dr E Scott Sills' letter (March $2005 J R S M^{1}$ ). These ladies, who made remarkable adaptations to their disability, should indeed not be forgotten, not only for their obstetric history, but as having provided one of the foundation stones of endocrinology. The 'official' report of their case in a now obscure Bohemian journal does not contribute to physiology, but a visiting German physician, Dr Karl Basch, reported in Deutsche Medizinische Wochenschrift (1910) that, when Rosa breastfed her baby, Josepha also lactated. He drew the conclusion - just after Bayliss and Starling's paper reporting the discovery of secretin and contrary to then accepted belief that lactation was controlled by the nervous system - that lactation must be controlled by something circulating in the blood, since that was the only functional connection between the two individuals.

In subsequent decades the principle underlying Basch's observation was put to extensive use in laboratory animals, usually rats, surgically united in 'parabiosis' and developing a shared capillary circulation, and the pharmacodynamics that determine whether substances cross from one individual to the other were unravelled. Notable areas of study relevant to medicine include elucidation of the control of gonadal hormone secretion by the pituitary and the discovery of erythropoietin. I used the technique in the 1950s to achieve the first demonstration of the function of (I now believe) leptin in the feedback control of food intake: rats in parabiosis with obese partners (made obese in several 
ways) greatly reduced their food intake and became extremely thin. I wonder whether I shall see this observation contribute to medicine!

\section{G R Hervey}

Department of Physiology, University of Leeds, UK (retired)

E-mail: g.r.hervey@btinternet.com

\section{REFERENCE}

1 Sills ES. Conjoined twins, delivery and the memory of medicine. J R Soc Med 2005;98:135-6

\section{Erdheim-Chester disease}

Dr Lee and his colleagues (April $2005 J R S M^{1}$ ) describe a case of renal failure in which the radiographic appearance of bone pointed to Erdheim-Chester disease, a histiocytosis. Among the organs affected in this condition they mention pericardium. We think it important to emphasize the frequency with which heart, pericardium and great vessels are affected. Recording 6 new patients with cardiovascular involvement, Haroche et al. ${ }^{2}$ have reviewed all 178 reported cases of Erdheim-Chester disease. 56\% had periaortic fibrosis, $44 \%$ pericardial infiltration and/or effusions and 31\% myocardial infiltration. Interestingly, 6 patients had a right atrial myxoma. Of the 58 patients with follow-up data, $31 \%$ died from cardiovascular complications.

\section{Benjamin Rhodes}

\section{Ali S M Jawad}

Department of Rheumatology,

The Royal London Hospital,

Bancroft Road, London E1 4DG, UK

E-mail: alismjawad1@hotmail.com

\section{REFERENCES}

1 Lee JHM, Stodell M and Fowler JC. Renal bone disease. J R Soc Med 2005;98:165-6

2 Haroche J, Amoura Z, Dion E, et al. Cardiovascular involvement, an overlooked feature of Erdheim-Chester disease: report of 6 new cases and a literature review. Medicine 2004;83:371-92

\section{Myocardial infarction after aspirin treatment, and Kounis syndrome}

Dr Fox and his colleagues (January 2005 JRSM $^{1}$ ) describe the case of a patient who developed coronary vasospasm after a dose of aspirin, to which she had a history of allergy. The concurrence of allergic reactions with acute coronary syndromes has been well described previously. Sometimes the allergic angina syndrome (Kounis syndrome) progresses to myocardial infarction. ${ }^{2}$ Various foods and drugs have been incriminated.
This syndrome is caused by release of inflammatory mediators during mast cell degranulation. These compounds include preformed mediators such as histamine, neutral proteases (tryptase, chymase) and platelet activating factor and also newly synthesized mediators such as leucotrienes and thromboxane which have been incriminated clinically and experimentally in production of coronary spasm and/or acute myocardial infarction. However, inflammatory mediators have also been reported increased in the blood or urine of patients with acute coronary syndromes of non-allergic aetiology $;^{3-5}$ moreover, degranulated mast cells have been found abundant in the coronary plaque rupture areas of such patients with recent myocardial infarction. ${ }^{6}$ For these reasons, we have suggested the existence of a final common pathway for allergic and non-allergic coronary syndromes. ${ }^{7}$

If mast cells do contribute to non-allergic coronary events, there is scope for therapy with stabilizing drugs such as sodium cromoglicate or ketotifen and with monoclonal antibody to IgE. Experimentally, Nemmar et al. ${ }^{8}$ have succeeded in abrogating late thrombotic events by stabilizing mast cell membrane with sodium cromoglicate and reducing inflammation with dexamethasone. We urge the research community to explore this possible final common pathway in allergic and non-allergic coronary syndromes.

\section{Nicholas G Kounis \\ Sophia N Kouni \\ Constantinos M Koutsojannis \\ Section of Medical Sciences, \\ Patras Highest Institute of Education and Technology, \\ 7 Aratou Street, Queen Olga's Square, Patras, Greece \\ E-mail: ngkounis@otenet.gr}

\section{REFERENCES}

1 Fox DJ, Gray TP, Fath-Ordoubadi F. Myocardial infarction after aspirin treatment. JR Soc Med 2005;98:21-3

2 Kounis NG, Zavras GM: Allergic angina and allergic myocardial infarction. Circulation 1996;94:1789

3 Clejan S, Japa S, Clemetson C, et al. Blood histamine is associated with coronary artery disease, cardiac events and severity of inflammation and atherosclerosis. J Cell Mol Med 2002;6:583-92

4 Takase B, Maruyama T, Kurita A, et al. Arachidonic acid metabolites in acute myocardial infarction. Angiology 1996;47:649-61

5 Filipiak KJ, Tarchsalska-Krynska B, Opolski G, et al. Tryptase levels in patients with acute coronary syndromes: the potential new marker in unstable plaque? Clin Cardiol 2003;26:366-72

6 Kovanen PT, Kaartinen M, Paavonen T. Infiltrates of activated mast cells at the site of coronary atheromatous erosion or rupture in myocardial infarction. Circulation 1995;92:1083-8

7 Zavras GM, Papadaki PJ, Kokkinis SE, et al. Kounis syndrome secondary to allergic reaction following shellfish ingestion. Int $J$ Clin Pract 2003;57:622-4

8 Nemmar A, Hoet PHM, Vermylen J, et al. Pharmacological stabilization of mast cells abrogates late thrombotic events induced by diesel exhaust particles in hamsters. Circulation 2004;110:1670-7 